\title{
More Than "Getting Us Through:” A Case Study in Cultural Capital Enrichment of Underrepresented Minority Undergraduates
}

\author{
Sarah M. Ovink • Brian D. Veazey
}

Received: 4 December 2009/Published online: 3 November 2010

(C) The Author(s) 2010. This article is published with open access at Springerlink.com

\begin{abstract}
Minority students continue to be underrepresented among those who seek graduate and professional degrees in the sciences. Much previous research has focused on academic preparation. Equally important, however, are the psychological-social barriers and lack of institutional support encountered by many minority students. We present a case study of a university-sponsored intervention program for minority science majors that addresses not only academics, but also socialization into the academic community, networking, and the ability to practice newfound skills and dispositions through undergraduate research. In examining this case, we suggest that concerted, formal efforts toward expanding habitus and thereby augmenting cultural and social capital may have positive effects for underrepresented minority (URM) college students' academic and career prospects. Moreover, we argue that these differences complement the gains program participants make in academic preparedness, showing that attention to academics alone may be insufficient for addressing longstanding inequities in science career attainment among URM students.
\end{abstract}

Keywords Cultural capital - Science · Undergraduate education · Underrepresented minorities · Institutional programs

\section{Introduction}

Our research focuses on an area of acute concern: the lack of underrepresented minority (URM) students pursuing careers in scientific and biomedical fields. Minority participation in doctoral-level scientific and biomedical research not only helps to broaden scientific inquiry, but also better serves the population-specific health concerns of these most

S. M. Ovink (两) - B. D. Veazey

Department of Sociology, University of California, Davis,

One Shields Avenue, Davis, CA 95616, USA

e-mail: smovink@ucdavis.edu

B. D. Veazey

e-mail: bdveazey@ucdavis.edu 
vulnerable groups (National Academy of Sciences 2005). According to a recent Council of Graduate Schools report, minority students (including Native Americans, African Americans, Asian/Pacific Islanders and Hispanics/Latinos) made up about $28 \%$ of all U.S. citizen and permanent resident graduate students in 2007 (Bell 2008). However, representation of minority students among fields of study was uneven. Minority students were much more likely to seek advanced degrees in education and business, for example, than in the physical, biological, and health sciences (Bell 2008, Table 1.7).

Participation rates of minority students in graduate education in scientific fields ranged from a low of $5.8 \%$ in earth sciences to a high of $9.5 \%$ in the biological sciences. In all, graduate school participation rates in 2006 fell far short of the $17 \%$ share of baccalaureate degrees in science and engineering earned by URM students in 2006 (National Science Foundation (NSF) 2009). Moreover, minority students continue to be less likely than white majority students to complete advanced degrees; URM students earned approximately $10 \%$ of science and engineering doctorates awarded in 2006, with whites earning about $76 \%$ (NSF 2009). While this is an improvement over just 3\% earned in 1975, minority students remain severely underrepresented among doctoral candidates in the sciences.

Racial/ethnic minorities represent a fast-growing group in the nation's colleges and universities. This growth offers an opportunity to answer recent calls to improve U.S. global competitiveness through an increased focus on preparing the next generation of skilled scientists and researchers (Council of Graduate Schools 2007; NSF 2008). Previous research has shown that the first 2 years of college are crucial for getting URM students into the science "pipeline." At present, half of students who show initial interest in pursuing a degree in the sciences change their plan within the first 2 years, and very few non-science students switch to science majors (Center for Institutional Data Exchange Analysis 2000).

Despite the wide variety of interventions that have attempted to fix the "leaks" in the science pipeline-from financial assistance to mentoring programs-little research has been conducted to investigate which approaches work best (but see Fox et al. 2009). Even fewer studies examine exactly what good programs actually do for successful minority students. What kinds of interventions achieve significant results? What can be done to effect lasting mobility among minority students who must serve as trailblazers, with few relatives or friends to look upon as mentors and examples? This last query touches on a subject little discussed in educational research and policy: whether and how formal educational systems can augment students' cultural capital. Bourdieu's (1973) concept of cultural capital refers to the specialized skill set- "knowledge, skills, and competence"children acquire from their environment (primarily parents, but also peers and schools) (Lareau and Weininger 2003, p. 597). These specialized skills may bring students "profit" in the form of good teacher-student relations, scholarships and job connections, but may also be detrimental depending on one's skill set and environment.

To address these concerns, we focus on the undergraduate experience of one such group-high-achieving (i.e., eligible for graduate study) minority students who participated in the Biology Undergraduate Scholars Program (BUSP) at the University of California, Davis (UCD). ${ }^{1}$ BUSP is an undergraduate intervention program with demonstrated success in increasing minority retention and achievement in the life sciences, as well as in helping such students acquire the knowledge, skills and competencies necessary

\footnotetext{
${ }^{1}$ Due to the unusual qualities of the case, we chose not to attempt to disguise the names and identifying features of UC Davis, BUSP, or BUSP's first two directors. We do, however, use pseudonyms for all other respondents to protect their privacy.
} 
for success in scientific and biomedical careers (Barlow and Villarejo 2004; Villarejo and Barlow 2007; Villarejo et al. 2008). Though this program is mainly academic in orientation, it also intentionally (and unusually) addresses students' lack of middle- and professional-class cultural and social capital: socialization into the academic community, networking (social capital), and the opportunity to practice these new-found skills and dispositions through paid undergraduate research experiences (UREs) that provide a training ground for academic and industry fields.

Numerous researchers have shown that URM students arrive at college less well prepared to excel at a rigorous science curriculum than their majority-group peers (Perna et al. 2009). In examining the case of BUSP, we background explicit discussion of BUSP's academic features to instead examine a less common question: How might concerted efforts by educational organizations to increase or enhance cultural and social capital improve student outcomes in the academic and scientific arenas? In the case of BUSP, our data suggest that efforts toward expanding habitus and thereby augmenting cultural and social capital may have positive effects for URM college students' academic and career prospects. Moreover, these positive effects complement the gains BUSP students make in academic preparedness, showing that attention to academics alone may be insufficient for addressing longstanding inequities in science career attainment among URM students.

Our findings are based on an in-depth interview study of BUSP alumni. We conclude with recommendations for future research into issues of cultural and social capital and college success, as well as suggestions for educational policy that aim to further the advancement of underrepresented minorities in the sciences.

\section{Literature Review}

A wealth of studies in the literature examine the barriers minority students face in attaining a college education, and in attempting careers in scientific and biomedical fields in particular (Fox et al. 2009; Hurtado et al. 2007; Perna et al. 2009). Despite controversial claims in the popular media that the U.S. has entered a "post-racial" era, evidence suggests that minority students still face pervasive discrimination in college environments (SuarezBalcazar et al. 2003). Moreover, racial/ethnic minorities are less likely to express satisfaction with their educational experience (Einarson and Matier 2005), a finding that supports the continued need for ameliorative programs to improve rates of retention and success among minority college students. In this review, we focus on the ways in which previous research has characterized the function of university-based programs aimed at retention of minority students.

Structured research programs and college retention projects have been credited with improving outcomes for minority students in the sciences. These types of programs may help minority students become inculcated into the "culture of science," improve social networks and academic skills, reduce feelings of social stigma and increase a "sense of belonging," learn to "identify" as scientists, and develop higher, more focused career aspirations earlier in students' college careers (Hausmann et al. 2007; Hurtado et al. 2008, 2009; Maldonado et al. 2005). Institutional climate and support in general has been shown to be important: characteristics of supportive institutions include the extent to which science is "normalized" as a career choice, provision of meaningful mentors and role models, and an orientation toward collaborative research (Perna et al. 2009; Shmurak and Handler 1992). The extent to which such programs provide opportunities for closer relationships with faculty and potential mentors may also be important for minority student 
success, since faculty-student interaction and mentoring relationships have consistently shown important benefits for underrepresented students (Bernier et al. 2005; Umbach and Wawrzynski 2005).

Fox et al. (2009) distinguish between programs for women in science and engineering that take an individualistic approach versus an institutional/structural perspective. This distinction is instructive because it focuses on the heart of the "problem" of integrating underrepresented groups: is college success the problem of the individual or the university? Must the student shape themselves into a simulacrum of the "successful" student (usually male and a member of the white or majority group) or is the structure that minority students meet too limiting and, therefore, must itself change? Fox et al. (2009) find that while ameliorative programs that work only on shaping the student are more common, programs that challenge existing institutions and structures are more often successful.

Few studies have used a cultural or social capital framework for conceptualizing the benefits that accrue to those who participate in undergraduate enrichment programs. However, as Pascarella et al. (2004) point out, “...students not only bring certain levels of cultural and social capital to college, the college experience itself provides a vehicle for acquiring additional cultural/social capital” (p. 252). Nevertheless, the authors do not consider formal, institution-initiated attempts to increase students' cultural and social capital. When the forms of capital are discussed, it is usually in the context of discussing the ancillary benefits of a largely academic- or research-focused program (Hurtado et al. 2008; Maldonado et al. 2005). We argue that a cultural and social capital framework increases our understanding of the barriers URM students face, and the ways in which undergraduate enrichment programs can target interventions to enhance URM students' chances of success in scientific and biomedical fields.

\section{Conceptual Framework}

The concept of cultural capital, first developed by sociologist Pierre Bourdieu and later adapted for use in various fields, has gained much currency among education researchers over the past two decades. Bourdieu examined how culture is used by elites as a means of maintaining power and prestige. In his conception, culture is a resource that can be monopolized, used to access scarce rewards, and transmitted from one generation to the next. Endowed cultural capital relates to individual agency through the development of a particular habitus (1984, 1986, 1990). For Bourdieu (1990), habitus is a system of classspecific dispositions that shape an individual's actions so as to reproduce and perpetuate existing systems of hierarchy. Thus, through early socialization experiences, we unconsciously internalize external opportunity structures and develop aspirations and expectations - and orient action-toward conduct we deem appropriate for "people like us." In this sense, habitus plays a major role in perpetuating inequality.

For Bourdieu (1986), cultural capital can take the form of embodied dispositions (i.e., class-specific tastes, preferences, consumption patterns, ways of inhabiting space, etc.), material objects, or educational credentials. Agents may also draw upon economic capital (e.g., money) and social capital (e.g., networks and connections with others). Bourdieu suggests that the amount and type of capital we possess - especially cultural capital-is a function of the habitus we develop in our class of origin. Consequently, elites' socialization experiences transmit the cultural capital necessary for the realization of their high expectations. Conversely, non-elites are socialized in ways that not only limit their expectations and aspirations, but this limited habitus fails to transmit the cultural capital 
necessary to navigate the institutions of the dominant class. In short, for Bourdieu, the accumulation and deployment of cultural capital is at the center of a strategic attempt by elites to maintain power.

Coleman (1988) elaborated the concept of social capital, defining it as a positive means of providing children with community norms, trust, and information. While Bourdieu's conception focuses on the constraining power of social capital through its monopolization by elites, Coleman's work suggests that providing social capital is a parental duty. As Dika and Singh (2002) have argued, “Coleman's work supports the idea that it is the family's responsibility to adopt certain norms to advance children's life chances" (p. 34).

Researchers focusing on the positive aspects of social capital-its capacity for building trust and community norms - have tended to rely on Coleman's interpretation (Dika and Singh 2002). Researchers examining differential schooling experiences by race/ethnicity, class, and gender have more often adopted a Bourdieuian perspective on cultural and social capital, examining the ways in which minorities and vulnerable populations are limited by the constraining power of capital (Lareau and Horvat 1999; Stanton-Salazar 1997, 2001; Olneck 2000; Lareau 2001, 2003; Horvat et al. 2003; Hassrick and Schneider 2009). Lareau (2003) identifies distinct, class-specific logics of childrearing: concerted cultivation (favored by middle-class parents) and natural growth (associated with a working-class upbringing) and argues that each leads to the transmission of different kinds of cultural capital. While Lareau does not claim that either style is inherently better, she argues that schooling systems clearly prefer the former, leading to increased opportunities for middleclass children and a smoother transition to postsecondary education and adulthood (Lareau and Weininger 2008).

Researchers attentive to differential outcomes by race/ethnicity find that when cultural and social capital matters for educational attainment, minority students are at a distinct disadvantage. Because minority students are typically economically disadvantaged relative to whites, they must struggle not only to acquire the economic capital necessary to attain a college education, but also the cultural capital that more privileged students simply inherit (Martin and Spenner 2009; Tierney 1999). Even middle-class status is sometimes not enough, since possessing status differs from knowing how to deploy status to one's advantage. Lareau and Horvat (1999) argue, for example, that middle class minority students face more of a struggle to capitalize on their middle class cultural capital than their majority white counterparts, in part because of the still-potent influence of race in everyday interactions. Privileged white students, in contrast, may be more likely to form and benefit from what Grodsky and Riegle-Crumb call a "college-going habitus," wherein both college attendance and success are largely taken for granted (Grodsky and Riegle-Crumb 2010). In sum, the accumulation of education-enhancing cultural capital and the formation of positive social ties that aid college attainment are more difficult for working class and/or minority students. Social hierarchies, such as those in the academic workforce, can be difficult to penetrate for students and families with little experience navigating higher education networks (Lin 2001). Working class skills, habits and styles may even be detrimental to the formation of positive social ties in the academic environment (Goddard 2003; Kingston 2001).

Frustration with the seemingly intransigent nature of cultural capital as described by such "deficit models" has led some to suggest that research move beyond documentation of the effects of the various forms of capital, and instead examine whether and how cultural and social capital might be developed for the benefit of disadvantaged and minority students (Tierney 1999; Goddard 2003). Especially as concerns the transition to college, a continued focus on students' families as their sole source of cultural capital may be 
misplaced, as young adults are largely expected to fend for themselves in the university environment. Tinto's (1987) widely cited model of university retention conceives of the college adaptation process as akin to assimilation to an "academic culture." Tinto argues that successful college students will replace their "home" culture with that of the academic culture. This approach, however, has been criticized as tantamount to "cultural suicide" (Tierney 1999). Maldonado et al. (2005) agree with Tinto that student integration into the university environment is important, but argue that integration can be accomplished in such a way that minority students do not feel they must leave their culture behind. Ameliorative programs, such as Student Initiated Retention Projects (SIRPs) and academic and social organizations dedicated to enhancing minority students' success can both integrate students into academic culture and conserve a sense of self and cultural tradition (Maldonado et al. 2005). However, little research has explored these projects as developers of cultural and social capital; rather, they are most often evaluated simply as purveyors of academic or moral support.

In sum, minority students and other non-elites are at a disadvantage when attempting the transition to college and persistence to a baccalaureate degree. Lack of economic and cultural capital not only limits students' possibilities, it also limits, as we will demonstrate, what possibilities minority students are even aware of. As Bourdieu and others have shown, the academic market tends to sanction and reproduce the distribution of cultural capital by proportioning academic success to the amount of cultural capital bequeathed by the family. However, we move beyond this argument to explore a seldom-considered question: how might concerted efforts by educational and social organizations succeed in increasing or enhancing students' cultural and social capital? In so doing, we also reflect on Bourdieu's suggestion that the conditions of capital acquisition matter; that is, that "learned" cultural capital will never appear as "natural" as that acquired through the process of growing up in one's own class of origin (Bourdieu 1984). Through our examination of BUSP and the undergraduate experience, we assess what might be termed community-directed cultivation - an organizationallydirected effort that attempts to augment the skills, habits and dispositions of entering URM students while supporting the maintenance of important ethnic, family and community ties.

\section{What is BUSP? A Brief Program Description}

The BUSP program began in 1998 with a fairly simple goal: to increase the graduation rate for minority students interested in the biological sciences. Targeted groups include students of Latino/a, African American, Southeast Asian (e.g., Vietnamese and Filipino) and Native American descent (see Table 1). Over time that goal expanded to include creating a supportive, academically focused community of minority students in the sciences and helping them to broaden and attain their professional aspirations by providing a wide range of information about their educational and occupational options.

BUSP's intervention strategy focuses on three main elements: supplemental instruction in core "gatekeeper" courses in chemistry, math, and biology; quarterly academic and personal advising; and paid UREs. As a multiyear "bridge" program, BUSP admits between 45 and 65 entering students each year who begin classes in the summer prior to their freshman year and continue through to the end of their sophomore year. After successfully completing their first 2 years, students may apply to take part in the BUSP Honors Program, which concentrates on conducting original research, writing and 
Table 1 Interview sample demographics

\begin{tabular}{llllllll}
\hline & $\begin{array}{l}\text { First generation } \\
\text { college }\end{array}$ & $\begin{array}{l}\text { African } \\
\text { American }\end{array}$ & $\begin{array}{l}\text { Hispanic/ } \\
\text { Latino/a }\end{array}$ & $\begin{array}{l}\text { Asian American/ } \\
\text { Pacific Islander }\end{array}$ & $\begin{array}{l}\text { Native } \\
\text { American }\end{array}$ & White & Total \\
\hline Female & 37 & 11 & 43 & 15 & 2 & 1 & $72(68 \%)$ \\
Male & 17 & 8 & 18 & 6 & 2 & 0 & $34(32 \%)$ \\
Total & $54(51 \%)$ & $19(18 \%)$ & $61(58 \%)$ & $21(20 \%)$ & $4(4 \%)$ & $1(1 \%)$ & 106 \\
\hline
\end{tabular}

presentation skills, and preparing students to apply to graduate programs. ${ }^{2}$ Apart from these formal strategies, BUSP also offers ready-made membership in a tight-knit subculture: "BUSPers," as participants refer to themselves, form study groups, room together, and socialize with one another. Program evaluations have shown that BUSP students outperform both non-BUSP URM students and white/Asian majority students in basic science courses, chemistry and calculus. Moreover, BUSP students' persistence to degree in biology majors exceeds the campus average (Barlow and Villarejo 2004; Villarejo and Barlow 2007). In sum, BUSP represents not only an educational enrichment opportunity, but also a supportive intellectual and social community for students of color interested in the sciences.

\section{BUSP as a "Case"}

A combination of unusual features makes BUSP a useful case: its comprehensive design, documented success, size and longevity provide a population of graduates sufficient to illustrate how concerted efforts by educational institutions can enhance students' cultural and social capital.

As many scholars have pointed out (Perna et al. 2009; Merriam 1998; Yin 2003a, b), case study methodology is appropriate when a phenomenon is particularly unique or the aim is to understand the importance of structure or context in a given situation. Moreover, by concentrating on the experiences of students in one program with a proven track record of success, we can identify which elements alumni found particularly meaningful and how they contributed to their individual academic and occupational achievements. While we acknowledge the limitations of case studies, our goal in this paper is not to generalize our findings to all educational institutions or even to all intervention programs; rather, our goal is to identify which intervention strategies were particularly effective in promoting success among URM students in the life sciences, and how they were experienced by their intended beneficiaries.

BUSP participants represent a variety of ethnic/racialized groups and their experiences were not uniform. Their level of disadvantage with reference to university preparation also differed; while about half of the students were the first generation in their families to attend college, the other half had parents who had attained a college degree and were able to offer a greater degree of support. Despite these differences, analysis of internal variation in the sample brought few significant differences to light. We do find evidence to suggest that the experience of African American BUSP students differed; for example, some African

\footnotetext{
${ }^{2}$ For a more detailed account of the programmatic elements of BUSP, see Villarejo and Barlow (2007).
} 
American interviewees reported greater difficulty in finding mentors. Still, our subsample of African American students ( $N=19 ; 18 \%$ of the sample) is too small to draw definitive conclusions. Likewise, while our findings suggest that BUSP may provide a more transformative experience for first-generation college-going students, these effects were not substantial. In sum, these internal variations, while not large, suggest important directions for future research on ethnic/racial and generational differences in the effects of programs like BUSP.

\section{Research Methods}

Our findings are based on the interview portion of a larger survey-interview research project. ${ }^{3}$ The BUSP Alumni Survey identified trends we explored in greater detail through in-depth interviews conducted from 2005 to 2006.

\section{Sample and Sampling Technique}

In 2005, we surveyed 201 BUSP Alumni who had participated in at least one academic quarter of the program and graduated from UC Davis between 1994 and 2004 with a BA or BS degree and had a minimum GPA of 2.7. ${ }^{4}$ The GPA minimum ensured that alumni were within range of graduate school eligibility requirements. All survey respondents were invited to participate in a longer, semi-structured telephone interview. A multidisciplinary team of researchers and graduate students gathered interviews from a total of 106 alumni, covering various aspects of alumni undergraduate experiences, and paying special attention to BUSP participation. Table 1 provides details on the sample by ethnicity and gender. As previously noted, all BUSP alumni interviewees are identified by pseudonyms.

\section{Data Collection and Analysis}

All interviews were conducted via telephone. On average, interviews lasted between 60 and $90 \mathrm{~min}$; however, several lasted $2 \mathrm{~h}$ or more. Each interview was recorded and transcribed by the interviewer within 1 week.

Once all interviews were transcribed, 15 were selected at random and analyzed individually by four members of the research team, using a set of codes developed from the 2005 BUSP Alumni Survey. Following this process, the research team reconvened to finalize the coding schema, critiquing the appropriateness of the existing codes and including additional codes based on the emergence of new themes. The interviews were then divided among three members of the research team and analyzed with the help of ATLAS.ti, a qualitative data analysis tool. To ensure inter-rater reliability, approximately $1 / 3$ of all interviews $(n=30)$ were read and coded by two or more members of the research team.

Interviews with two former BUSP directors (Merna Villarejo, the founding director, and Gina Holland, her successor) were conducted in 2008. These interviews primarily addressed the origins of BUSP as an educational organization, as well as an important background question: What are the specialized skills required for successful integration

\footnotetext{
${ }^{3}$ For details on survey findings, see Barlow and Villarejo (2004), Jones et al. (2010), Villarejo and Barlow (2007), and Villarejo et al. (2008).

${ }^{4}$ For a more detailed account of the 2005 BUSP Alumni Survey methodology, see Villarejo et al. (2008).
} 
into the academic/scientific environment at UCD? Villarejo was a tenured professor at $\mathrm{UCD}$, and both directors were research scientists, so they were able to speak with some authority as to the academic and professional standards necessary for success in the discipline.

In the data sections that follow, we examine the BUSP experience through the eyes of alumni and former directors. We follow an inductive, grounded theory approach to data analysis (Strauss and Corbin 1990). We identified recurring patterns and interrelationships by means of thematic coding, wherein categories of analysis emerge from the data (Bowen 2006). This approach led us to focus on the three elements of BUSP that alumni reported as important for their success at UC Davis and beyond: advisors, peer group culture, and the experiences gained via the URE. We begin each section by reflecting on the directors' perspectives on the importance of each of these main elements. We then provide the reader with a window to the experiences of URM students, with attention to how each of these three areas of influence within the BUSP program affected students' undergraduate experiences, formation and appreciation of cultural and social capital, and career goals and accomplishments.

\section{Experiencing BUSP: Three Factors for Success}

Factor One: The Importance of Advisors

The factor BUSP alumni identified as most important for their academic and professional success was the guidance they received from BUSP advisors. Both alumni and directors discussed how advisors helped students navigate the complexities of an unfamiliar institutional environment and intervened in ways that were pivotal to students' overall success. As we will show, the individualized advice and direct interventions that are the hallmark of BUSP advising became important mechanisms though which advisors transmitted the cultural capital required for life-long academic and professional success.

\section{Directors' Perspective: Personalized Advice and Direct Interventions}

All BUSP interviewees were members of racial and ethnic minority groups, and about half were the first in their families to attend university. As such, many BUSP alumni lacked at least some of the skills, knowledge and dispositions their middle-class/majority counterparts frequently took for granted-in particular, college-educated parents who could act as informational resources for students planning academic careers. As one former director said:

There's just a lot of savvy, if you like, that students who are from college-going backgrounds, college-going families, have that's just been transmitted [from their parents] that students who aren't from those backgrounds don't have.

-Gina Holland, Former Director, BUSP

Recognizing how this deficiency in "savvy" can put minority students at a disadvantage, one major goal of BUSP was to provide advisors who could help students navigate this unfamiliar institutional context. In their first year, BUSP students are required to meet quarterly with an advisor who goes over their grades and course history closely, monitors important deadlines, and suggests a schedule and academic course structure tailored to their strengths. The BUSP approach contrasts with that of other academic programs at UC 
Davis, most of which do not require meeting with an advisor until the student's junior year. Having frequent and personal advising helps foster larger, more robust social networks between students and faculty, as advisors recommend particular courses or professors or suggest other mentoring opportunities.

According to the directors we interviewed, BUSP advisors provide two important functions: reliable and timely advice that is individually tailored, and a willingness to directly intervene in students' academic journeys. In a typical quarterly advising session, the advisor goes over the student's academic records and helps them to develop a specific, achievable plan:

[We] look at grades, you know, so if you're planning on registering for three science classes next quarter, and you took out [earned] C's in your science classes this quarter, or you're getting C's in your midterms, the advisor will say, 'Uh-uh. Two max. You can't take three science classes at a time, you can't handle that. Choose something else.'

-Merna Villarejo, Founding Director, BUSP

Since BUSP's inception, advisors have played a key role in the success of its students. As we will see below, the alumni we interviewed were likely to agree with this assessment.

\section{Alumni Perspective: Personalized Advice and Direct Interventions}

When asked how BUSP advisors influenced their career interests in college, nearly all the students in our sample mentioned the instrumental nature of their interactions, expressed in terms of "getting us through" or "keeping us on track." Advisors helped in planning and pacing schedules, selecting courses, monitoring compliance with prerequisites, advising them of various deadlines, and providing support and encouragement along the road to graduation. In many cases alumni reported that BUSP advisors also directly intervened in ways that had profound consequences for their long-term success. In short, BUSP advisors functioned as a motivational and informational "one-stop shop" students felt comfortable engaging whenever they needed information, a morale boost, or a trusted guide to open their eyes to new possibilities.

Contemplating the importance of BUSP advisors to her undergraduate career, Maricela's experience is fairly typical of how BUSP advisors' personalized advice can transmit that "savvy" former directors identified as necessary to succeed in the sciences at UC Davis.

I was the first one in my family to go to college...so [my parents] really didn't know how to help me or advise me... Getting into the BUSP program where you had these advisors you could talk to was so important. They were there in terms of how to choose courses, what needed to be in your schedule, when you were taking what. They were always making us aware of what course requirement we needed, making sure we were doing what we were supposed to be doing. To have that guidance was what really made the difference for us, I think.

-Maricela, Nurse Practitioner

Maricela's description encapsulates the dilemma that faces students who must struggle to develop college-savvy skills. Knowing how to choose courses or plan a schedule may sound like something any 18-year-old could handle, but as previous research has found (Lareau and Weininger 2008), such knowledge is part of a decidedly class-based skill set that college-educated parents both formally and informally pass on to their children. 
Lacking access to such networks, students like Maricela are at a distinct disadvantage. Moreover, children whose parents support the desire to attain a college education, but to whom children cannot turn to for advice, often suffer crises of confidence that may have real consequences for their academic strivings.

They [my parents] have always been supportive of education...they still are very supportive. But half-way through high school they sort of stopped guiding me because they didn't know anything more then, at the time they weren't versed in higher education ...In high school I told them I wanted to be a doctor and from that point on, I think I was like 16 years old, I was going to be the doctor of the family...So at the time I finished high school, there had been so much pressure for me to be this doctor that I hated it...Honestly I was scared because I didn't think that someone like me could actually go to medical school. I knew nothing about it, but it just didn't happen in my family.

-Joel, MD Student (emphasis added)

Later on in his interview, Joel describes his advisor as a "source of strength," who, through helping Joel schedule the appropriate courses and telling stories of "others who have made it" motivated Joel to stay on the path toward medical school. Similarly, Christa, who now works with domestic violence survivors, reported that it was "really motivating" to see women in top positions who were also "of color," such as BUSP directors. There was an "understanding with people of color, like this struggle you have to go through...like all this crap you have to deal with but you can still be successful and be a leader." Thus, the skills and knowledge advisors transmit to students, as well as the motivational support they offer, function as a form of cultural capital, which Maricela, Joel and many others argue "really made the difference" in keeping them on track to their undergraduate degrees.

\section{Direct Interventions: Roadmaps and Redirecting}

Sometimes BUSP advisors took a decidedly "hands-on” approach. When alumni aimed too high or too low, BUSP advisors intervened to suggest alternative academic and career options or helped to redirect their energies toward a career path that was a better "fit." Many alumni we spoke with mentioned how their advisor sat down with them, assessed their "superior" abilities, and then tailored a multi-year roadmap to help them reach their goals. Tomás' experience is a good example of how this process works:

In one afternoon, [my BUSP advisor] basically plotted out three years of work for me...She gave me a roadmap for what I needed to do...she knew my strengths to the point where she knew I could actually apply to and get into Princeton...I remember starting out that conversation...saying I could get into Sacramento State or something like that, and she corrected me right off the bat and said, 'You're in a different league. You're a different type of student. You shouldn't be thinking about that, you should be thinking about this.' So by following what she said, that led me to get a Master's degree at Princeton [which led to a job] in Congress and so forth.

-Tomás, Lobbyist

What Tomás calls a "roadmap" was in fact something much more profound-by paying attention to his strengths and abilities and "correcting" his goals, Tomás' BUSP advisor altered his post-graduation planning in a way that had major consequences for his longterm career success. In much the same way that middle class parents guide and intervene in their children's educational planning, the direct intervention of Tomás' BUSP advisor 
provided a form of cultural capital, transmitting a particular vision of what was possible for him, and allowing him to adjust his aspirations to something he had never considered on his own - the possibility of pursuing a graduate degree at an Ivy League university.

Sometimes the rigorous prerequisites for medical school or graduate training in the sciences may not be the right fit for a student's abilities or interests. Problems of "fit" are not unusual; Kramer et al. (1994) found that nearly $75 \%$ of undergraduates surveyed at Brigham Young University changed majors. However, for minority and first-generation college students, a mismatch between ability/interest and the curriculum may be an especially agonizing source of self-doubt, compounded by the lack of a financial and emotional "safety net" more often afforded majority and middle-class college students who change career goals. BUSP students often begin college with a focus on attaining certain highly visible, professional careers in the sciences such as doctor or pharmacist, and have fewer resources to fall back on should they fail in this attempt. Many BUSP students who did eventually change their career intentions reported fearing to disappoint their parents, who had counted on having a "doctor in the family." BUSP advisors' redirecting strategies can help students to refocus their energies toward a more suitable career path while being sensitive to the extra pressure BUSP students often feel.

Like many BUSP students, Julia started UCD with a desire to become a physician. Her family was influential in this decision; as she put it, "I think that there was a lot of hope riding on my shoulders...I got a lot of, 'We want you to do what makes you happy,' but, 'A doctor is really cool, a lawyer is really cool,' that kind of thing." Yet as the science courses became increasingly difficult, Julia started to struggle. She knew she would have to make some changes, yet she did not want to "give up" her childhood dream. A timely meeting with her BUSP advisor offered Julia a "healthier perspective:"

My BUSP advisor...saw how much I was struggling and one quarter said to me, 'No more science classes, let's take a break. Let's just talk about what classes you've enjoyed, what's interesting to you. Let's take some of those classes.' And I did. When that happened, it was much easier for me. Because I didn't want to give up...taking all of the science classes, to me I had looked at it as though I was quitting, so that didn't sit well with me. [My advisor's] point of view is that 'it's not that you are quitting, it's that you're finding something that you enjoy.' So she helped me, I think, have a healthier perspective.

-Julia, Social Worker

Julia's advisor did not discourage her from taking science courses; rather, her advisor's suggestion to "take a break" allowed Julia to explore courses she found more interesting, leading her to an entirely different—-though equally satisfying-career.

While it may be tempting to argue that these redirecting strategies cause students like Julia to downgrade their original aspirations, Julia's own interpretation suggests that her advisor's intervention actually expanded her awareness about her career options. As such, redirection, like road maps, is especially instrumental for students whose families may not have access to forms of cultural or social capital that would allow them to provide specific career advice. As Alicia, now a laboratory technician, put it, the extent of her family's career guidance was, "Basically, that I should be a doctor or I should stay at home and work and help the family." Advisors can therefore provide knowledgeable guidance as well as a safe space for students to investigate alternative careers without feeling like a "quitter."

In sum, BUSP augmented minority students' cultural capital by providing advisors who acted similarly to what some scholars (Lum 2006) have identified as middle class "helicopter parents"- hovering over students to make sure they were ready for each step along 
their academic journey. In some instances, advisors were able to offer culturally sensitive advice to help minority students surmount motivational roadblocks-providing confidence that "someone like me" can succeed in the university setting. Moreover, these advising strategies not only helped students realize the range of available career options, but also worked to align their aspirations in ways that increased the likelihood for their overall academic and career success.

\section{Factor Two: Social Capital and an Alternative Intellectual Community}

The second factor alumni identified as especially salient to their academic and career success was ready and immediate access to a community of like-minded peers. While "peer climate" and contexts have shown promise in explaining students' persistence to degree completion, little research has explored peer context in depth (Oseguera and Rhee 2009). Many sociologists and anthropologists, however, have shown that the social and cultural practices youths develop within their respective youth cultures not only provide imaginary or socially constructed identifications for members (Ajrouch 2004; Hebdige 1979), but in some circumstances the routine practices of members can transmit a type of "subcultural capital" (Thornton 1996) that functions as a vehicle for the accumulation of status both inside (Hebdige 1979; Jensen 2006; Thornton 1996) and outside (Bettie 2003; Nisbett 2007) their peer groups. One of the most valuable services BUSP performed, therefore, was to provide entering freshmen immediate access to an alternative community of minority scholars where success in the sciences became "normalized." The empowering subculture and set of expectations and practices associated with this institutionalized space became a source of social and cultural capital from which students could draw.

\section{Directors' Perspective: An Alternative to Politically Focused Organizations}

When BUSP began, the primary focus of minority student organizations at UC Davis was either political or social. Students found participating in these organizations to be a rewarding experience, but as Merna Villarejo pointed out, these clubs "involved tremendous commitments of time, and [students] really couldn't participate in five-hour [organization] meetings every night and still get [their] calculus homework done." Moreover, directors were cognizant of the fact that high-achieving students of color who chose to focus on their studies rather than participate in minority student activities were sometimes accused of "acting white" or "selling out" (Fordham and Ogbu 1986). Discussing the initial design of the program, Villarejo reflected on the alternative intellectual community she hoped BUSP would foster:

[Minority] students found themselves in the position of either being part of their racial or ethnic group in a social and political sense, or doing their science; and if they were doing their science, they were "Oreos," or whatever the equivalent terms are for other groups. So we wanted to build a community where students...could reinforce that interest they had [in science] and not feel like they had to be "acting white" to do this. And that was a very conscious part of the design.

-Merna Villarejo, Founding Director, BUSP (emphasis added)

From its inception, then, one of the most important ideas behind BUSP was to create an institutionalized space where it was not unusual to be a person of color and a science major. In fact, Gina Holland reported that during her tenure, which began 10 years after BUSP's inception, creating a community of scholars of color was as needed as ever because minority students were still being "diverted into cultural activities that were antagonistic to 
[succeeding as a student] and were still likely to be accused of 'selling out' for being high achievers." As we will see, this alternative community approach appears to have worked. By creating a space where academically focused minority students could easily find one another, students felt a strong sense of belonging and quickly found themselves immersed in a supportive subculture where success in the sciences became the norm.

\section{Alumni Perspective: An Alternative Intellectual Community_The BUSP Subculture}

Being one of the few minority students in introductory science classes largely dominated by whites and Asians could be an alienating experience. ${ }^{5}$ This sense of social isolation was especially pronounced in a politicized environment in which the very term "minority" was often associated with "undeserved" admissions through affirmative action policies. "A lot of times [non-minority] students were like, 'Oh, we don't want to work with you,'” recollected Sola, currently in medical school, "They thought you weren't capable-as a peer, as a college student-like you didn't belong there."

In such an environment, the need to connect to a community of peers is especially acute. Therefore, early and effortless access to a group of students they could "identify with," who were "going in the same direction" helped to ease the sense of isolation students felt as a person of color at UC Davis:

I think the biggest thing BUSP gave me was finding a group early on that I could identify with without really having to make an effort. I know this because my girlfriend's two younger sisters are at UCD right now and...it's a lot harder on them...because they have to make the effort to find people of color in [a] college where there's not many of us... [As a part of BUSP] I had an entire group of them right off the bat... The camaraderie with the other students that you could relate to early on was the biggest-absolutely biggest thing that BUSP does-more than the teaching and everything else, just making sure these students, who are all going in the same direction, stay around each other.

-Odis, MD Student (emphasis added)

The sense of community BUSP managed to nurture was so strong that eventually an empowering subcultural identity developed among its constituents, complete with a set of rituals, role expectations, and a specialized vocabulary:

All of us were BUSPers. All of us were going to be doctors or MD/PhD people...We always had the highest grades. We threw the curve. There was a sense of competition but also a sense of [camaraderie]...supporting each other and making sure we all did well...Also having BUSPers in a lot of courses reduced the sense of social isolation...I sat with BUSPers throughout most of my science courses, and it was nice to see familiar faces... and knowing that together we were going to do well, we were going to bring in the best grades.

-Tasha, Physician

As Tasha's quote illustrates, alumni derived a strong sense of pride from their association with this community of high-achieving scholars. Rituals such as sitting with fellow BUSPers, competing for the highest grades, "making sure we all did well," and even the

\footnotetext{
5 Although a small number of Asian students are members of BUSP, these students are nearly all from groups still underrepresented at UC Davis (including Filipinos and students of Southeast Asian extraction). See Table 2.
} 
Table 2 Undergraduate student population by race/ethnicity (fall 2008)*

\begin{tabular}{|c|c|c|c|}
\hline & $\begin{array}{l}\text { Undergraduates } \\
\text { (count) }\end{array}$ & $\begin{array}{l}\text { Asian and Hispanic } \\
\text { pan-ethnic groups (count) }\end{array}$ & $\begin{array}{l}\text { Total by pan-ethnic } \\
\text { group (percentages) }\end{array}$ \\
\hline African-American/Black & 716 & \multirow{10}{*}{9,727} & $3 \%$ \\
\hline American Indian/Alaska Native & 155 & & $1 \%$ \\
\hline Chinese/Chinese-American & $4,437)$ & & \multirow[t]{8}{*}{$40 \%$} \\
\hline East Indian/Pakistani & 920 & & \\
\hline Filipino/Filipino-American & 955 & & \\
\hline Japanese/Japanese-American & 416 & & \\
\hline Korean/Korean-American & 649 & & \\
\hline Pacific Islander & 115 & & \\
\hline Vietnamese/Vietnamese-Amer. & 1,383 & & \\
\hline Other Asian & 852 & & \\
\hline Mexican/Mexican-Amer./Chicano & 2,325 & \multirow[t]{8}{*}{3,078} & \multirow[t]{3}{*}{$13 \%$} \\
\hline Other Spanish-American/Latino & 752 & & \\
\hline Other Hispanic & $1)$ & & \\
\hline White/Caucasian & 8,536 & & $35 \%$ \\
\hline Other & 459 & & $2 \%$ \\
\hline Ethnicity unknown or not stated & 1,041 & & $4 \%$ \\
\hline Non-U.S. citizens & 497 & & $2 \%$ \\
\hline Total headcount & 24,209 & & $100 \%$ \\
\hline
\end{tabular}

*University of California, Davis: University Communications (June 2009)

use of the term "BUSPer" to refer to group members helped to build a sense of community while symbolically reinforcing notions of what was expected for the group-namely, academic success and high career expectations.

This reputation for success, as Marcela notes, may also have helped to change others' poor opinions of underrepresented minorities in the sciences:

All of us in BUSP came from such different places. It was nice to have the BUSP program...you could feel like you belonged. [With] the tension over the affirmative action thing...there was this expectation that, as persons of color, we were not as smart. The white kids would be like, "You took my spot." I remember we took calculus and we all scored Bs and the professor was really surprised. He realized that these kids are smart.

-Maricela, Nurse Practitioner

Whether or not others' opinions were actually changed, the perception that BUSPers were challenging prevailing stereotypes appears to have decreased any sense of social isolation they may have felt, and further strengthened their attachment to this strong subculture.

\section{Alumni Perspective: An Alternative Intellectual Community-Peer Support and Subcultural Capital}

Feeling a "sense of belonging" was only part of the benefit of participating in BUSP. Time and again, alumni credited the academic, emotional and motivational support they received 
from peers as essential to their success in college and beyond. BUSP students helped one other with challenging classes; shared information about deadlines, requirements, and other useful tips; kept the pressure on one another to keep grades high; and generally did their best to motivate one another.

A lot of us, maybe all of us are first-generation college students and we really didn't have family who knew what to expect-they couldn't help us so we helped each other. It was like we were all making sure we got all the necessary information to get where we wanted to go. Helping each other with the courses we needed to take, making sure we studied and got the grades we would need...

-Maria, AmeriCorps Alumna and Medical School Aspirant

Being in BUSP, a lot of people were interested in some type of science career, and the first two years when we were taking those chemistry and math classes, we would study together, and we would help motivate each other... and that helped me to succeed...So just being with people like that...we'd kind of motivate each other, and that helped a lot.

-Pedro, Doctoral Candidate, Physiology

It comes as little surprise that alumni drew from an emotionally laden vocabulary when discussing the support they received from their peers. The actions students describe are indeed encouraging forms of support that might be useful for any undergraduate. However, it is important to recognize that such support is embedded in a set of day-to-day practices that define and redefine what it means to be a "BUSPer" in particular. As such, these routine activities appear to serve as important mechanisms for transmitting BUSP's "brand" of subcultural capital. In much the same way that rituals, role expectations and a specialized vocabulary symbolically reinforced the behaviors and aspirations BUSPers are expected to exhibit, the practices constituting the "emotional, motivational and academic support" BUSPers praised so highly appear to transmit a useful set of skills and dispositions that make those behaviors and aspirations possible. This transmission process is best illustrated by another quote from Odis.

I was pretty lazy early on. Like really lazy. The only reason I would study sometimes was because I could study with friends. When I finally got to the point where I decided to step it up, I was not in too bad of a position...If I hadn't had that support early on, I would have been worse off...

-Odis, MD Student (emphasis his)

Surrounded by studious friends, Odis developed an orientation to study even at those moments when he did not feel like it. Once he became serious about his academic career, Odis could draw on the social and cultural capital he had accumulated from peers: stores of technical knowledge, a set of effective study skills, and a network of supportive "study buddies" that made "stepping it up" a viable possibility.

Just as directors envisioned, the sense of community BUSP fostered did indeed create an alternative space where minority students could concentrate on science. Ready access to a community of like-minded peers decreased the sense of alienation many alumni felt when they arrived at UC Davis. Moreover, this powerful subculture's rituals, role expectations, and specialized vocabulary generated a set of culturally-sanctioned behaviors and practices that transmitted important forms of social and (sub)cultural capital alumni could rely on as they progressed through their undergraduate careers. 
Factor Three: The Undergraduate Research Experience (URE)

The third BUSP factor alumni identified as especially valuable was the URE. Recent research supports the importance of UREs; these experiences not only enhance students' educational experiences, but also correlate with persistence to baccalaureate degree attainment and enrollment in postgraduate study (Bauer and Bennett 2003; Jones et al. 2010).

For many URM students, particularly first-generation college attendees, the science career professionals they are most likely to encounter are family physicians or pharmacists. Therefore, it is not surprising that at college entry most BUSP alumni aspired to careers in medicine. Stella, a Latina alumna, put it this way:

When I first entered UC Davis all I was interested in was being a doctor because with my background, you don't really get exposed to very many people [with] different career paths...I didn't really know that doing clinical research was an option. I just wanted to be a pre-med [student]... I didn't know you could [work for industry]. I had no idea you could actually be a pharmacist and not work at Longs [Drug Store]. -Stella, Senior Clinical Trial Manager

While BUSP's URE may not have swayed a staunch pre-medical student from her desire to become a doctor, in some cases it did throw open the doors to previously unknown career paths. Even if students did not follow a research career after college, the URE can still be transformative. Both the directors and alumni stressed that exposure to research as an undergraduate not only helps students determine if research is a good career fit, but when thoughtfully designed, the URE can also augment students' cultural capital in ways that support success in the sciences at UC Davis and beyond. Moreover, the URE functions as a "trial field" or staging ground in which BUSPers are given a safe space to practice their newly acquired cultural capital before facing the "real" fields of academia or scientific industry.

\section{Directors' Perspective: The "Good Fit"}

The student who begins his/her undergraduate career planning to become a research scientist is rare. Rarer still is the minority student with such plans. The URE was designed to expose URM students to the myriad career possibilities in the life sciences and then provide a taste of life as a research scientist. In so doing, the URE also addresses important cultural and social skills particular to the sciences-how to behave professionally, how to collaborate in a lab environment, and how to perform the role of a teacher-scholar or scientist.

As Villarejo explains, BUSP's URE is a de facto requirement for future graduate study because it allows students to see whether research is a "good fit" for their own skills and interests.

You have to have the curiosity to want to ask questions, you have to have the selfdiscipline to make yourself get up in the morning, and do the work, it's a completely different kind of world...[Undergraduate students] need experience doing research to get some sense of whether it's a good fit.

-Merna Villarejo, Founding Director, BUSP 
Directors also stressed that to be successful in the sciences students need to possess a very specific set of technical and soft skills. As Gina Holland explained, BUSP was equally concerned with grooming URM students to be professionals. The URE and related Lab Skills course (which taught technical laboratory skills along with professional protocol) became mechanisms through which cultural capital was transmitted.

[We taught] students how to be professionals...To exist and succeed in an academic environment, it helps if you know business and academic etiquette, and that was a big part in the Lab Skills course... and if you're not from a culture like that, learning how to code-switch is required to be successful. The tendency is that people, whatever the culture, are going to assume that you know the rules. If you don't, you stand out, and you're not going to get into the clubhouse.

-Gina Holland, Former Director, BUSP

Cognizant of the fact that minority students were less likely to have access to resources that would transmit such forms of cultural and social capital, BUSP directors designed the URE to provide that set of technical and soft skills necessary to ensure that minority students were on par with their majority counterparts. Also, the URE was paid, which removed a potential roadblock to participation for poor and working-class students who might otherwise have sought outside employment.

\section{Alumni Perspective: The "Good Fit"}

How did alumni experience undergraduate research, and why did they feel it was so essential to their long-term success? Dori developed an early interest in research, so she actively sought out research experiences in two laboratories to make sure a career in research was a good fit.

Early on I thought I wanted to do research, so I wanted to be exposed to it to be sure there wasn't something I'd really hate about it... and my experiences reinforced the idea that scientific research kind of suited me-my personality and my interests. -Dori, Ph.D. Candidate, Cell Regulation

Marta, who is currently involved in academic research, entered UC Davis with a desire to be a veterinarian. Dissatisfaction with her coursework and an uninspiring internship in a hog barn made her realize that a career as a veterinarian was not going to be satisfying. Not only did Marta's URE allow her to see that research was a better fit for her than veterinary medicine, it also opened her eyes to a range of careers she had never considered:

The courses I took in animal science weren't interesting to me. They weren't what I thought animal science was going to be...I saw the big picture [in my research experience]...it introduced me to something I didn't do before. I never knew there were jobs like that.

-Marta, Ph.D. Biology

George began college with the goal of becoming a physician. His research experience informed his decision to take a job as a lab technician once he graduated.

When you first start you have tunnel vision, you think 'medical school, medical school' only, 'medical school'... Then you start to realize that there are other things out there. So, the lab work made me realize that there's work to be done in science as 
well. You can either be a scientist working in a laboratory or working in biotechnology.

-George, Senior Lab Technician

Other students had similar revelations; even if they did not change their goals to include a research career, simply having a choice and knowing "what's available" was valuable.

So for Dori, Marta, George and many other students, exposure to research as an undergraduate did in fact allow them to see if research was a good fit with their abilities and interests, for it provided an opportunity to practice the role of a researcher and "envision" what their lives as research scientists might really be like. Moreover, undergraduate research opened the door to previously unknown research-related careers. Whether or not they chose research careers after graduation, exposure to research augmented BUSP students' stores of cultural capital. Learning the skills, knowledge and dispositions of the scientific community, and also having a chance to deploy those skills in a realistic yet safe "trial field," allowed them to make a calculated decision about their chances for future success in such roles.

\section{Alumni Perspective: Grooming Function-Technical and Soft Skills}

Many alumni, acutely aware of their cultural disadvantages vis-à-vis majority students, credited BUSP with building their confidence in several areas. The mechanisms that built this confidence were most notable when they spoke about their research experiences.

Marcella, now an epidemiologist, stressed that her URE and related Lab Skills course gave her a chance to develop the technical skills a professional in the sciences ought to have-specifically, learning how to read and discuss scientific journal articles, participating in professional meetings, and practicing her presentation skills:

[We] had other classes where we would talk about research, hear researchers talk, or practice our presentation skills. Those are life-long skills that have stayed with me. When I do a presentation, I'm able to stand up there, and I know what I [should and] shouldn't be saying. Or looking at a paper, taking a paper piece-by-piece, those kinds of things were invaluable experiences.

-Marcella, Epidemiologist

Similarly, Stella described how her research experience allowed her to develop the soft skills, or professionally appropriate ways of behaving, necessary for a professional career:

[In the lab] you see how professionals behave in a professional setting....and you're like, 'Oh. This is what professional people act like,' and 'This is how you're supposed to respond.'....My dad is a garbage man. So when I would come home and tell him, 'Oh my boss did this, this, this, and this,' my dad would be like, 'Well tell him to leave you the hell alone!' [chuckles] And I'd have to explain, 'Hey Dad, I can't do that'...He's a garbage man, so I'm sure that's how it works in his job, but that's not how it works here.

-Stella, Senior Clinical Trial Manager

In addition to the technical skills she developed working in a research lab, Stella also learned the cultural and behavioral norms of the particular occupational community to which she would ultimately belong. Moreover, her comments highlight—perhaps to an extreme-how the "advice" of well-meaning parents could potentially jeopardize the hard-won professional success of their children. Thus, the grooming function, and 
especially its ability to transmit requisite technical and soft skills, is an essential part of augmenting students' cultural capital in ways that ensure durable academic and career success.

For some students, the URE led directly to a student's next step, through providing the skills necessary for a biotechnology job, or recommendations from URE supervisors that paved the way to postgraduate schooling. Nora, now a health care consultant, credited her URE with "[enabling] me to get a job right out of college, there were no concerns at all. I had several offers because I had practical experience and not just the theories behind the biochemistry degree." Claudia, now a veterinarian, reports also getting a lot of "value" out of her URE, though she did not pursue a research career:

So all these research-oriented jobs [UREs], I got a lot of educational value from. Not to mention they were paid jobs and a lot of them actually led me to my letters of recommendation, but they all kind of reinforced the fact that research was not going to be for me. But it did help open doors in terms of getting into vet school, and I knew it would do that.

-Claudia, Veterinarian

In sum, the URE augmented the cultural capital of URM students, whose knowledge of the breadth and depth of career opportunities in the sciences tended to be less than that of majority/white peers. The URE provided BUSP students with an opportunity to see if research was a "good fit" and broadened their knowledge of career options in the sciences. Likewise, the ability to form larger and more robust social networks that included research faculty and postdoctoral scholars was important for expanding BUSP students' social capital. Indeed, these networks often proved more important than the research work itself for enhancing students' career trajectories. The URE also transmitted a specific set of technical and soft skills common among members of the professional or academic scientific communities, and in some cases provided tangible benefits in the form of job experience and recommendations for next steps in students' academic or professional careers.

\section{Discussion: Providing Cultural Capital in the University Environment}

As an academic enrichment program, BUSP succeeds in helping URM students attain the skills needed to succeed in science-related majors and careers. As previous program evaluations have shown, BUSP alumni are more successful than both non-BUSP underrepresented minorities as well as white/Asian majority students in completing science degrees. Even alumni who left the biological sciences credit the BUSP experience with enriching their undergraduate experiences.

While BUSP's supplemental instruction might help virtually any undergraduate student to improve their performance in chemistry or calculus, BUSP's combination of academic enrichment with attention to URM students' cultural and social capital is unusual. In the foregoing data, we saw that BUSP is particularly helpful to URM students struggling to navigate issues not pertinent to most majority white and Asian students, such as bridging the cultural expectations of home with the expectations of the university environment (Maldonado et al. 2005). 
"More Than Getting Us Through"

We find that the overall effect of BUSP, through the three elements of advising, the URE, and providing peer support, was to shape students into future professionals. BUSP advisors and instructors not only hovered over students and kept them on track, they also taught the skills that would help URM students move forward after leaving BUSP. Dealing with professors, what to say and do during interviews, how to interact with lab colleagues; all of these elements, great and small, are typically part of the middle-class cultural capital inheritance. BUSP advisors sought, in a very short amount of time, to augment URM students' cultural capital through explicit lessons in subjects most middle-class students unconsciously absorb throughout their childhood. By most alumni accounts, the lessons were a resounding success.

Peers were also important. As Holland points out, the road to a college degree is still "rocky" for URM students, however much the achievement gap may be closing. Being the sole "brown face" in a sea of majority whites and Asians can be daunting. Alumni maintain that having immediate access to a supportive community of like-minded peers helped to decrease any sense of social isolation they may have felt. Moreover the behaviors and aspirations which became hallmarks of the BUSP "subculture" generated a set of practices that transmitted important forms of social and (sub)cultural capital, making even the loftiest aspirations seem more attainable. Providing an institutionalized space where scholars of color could gather and support one another appears to be an additional way BUSP facilitates the expansion of capital among URM students.

Finally, the URE was also instrumental. Working with professors and graduate students in the lab-particularly if their placements included minority researchers or graduate students-helped BUSPers to imagine themselves pursuing similar careers. They learned to work as a member of a team, to seek out mentors, and to behave professionally. Many alumni increased their stores of social capital by forging connections that were important for getting into graduate school (through personal recommendations and networks) or led directly into a post-college job. In sum, the URE provided a space, or specialized trial "field" in the Bourdieuian sense (Swartz 1997) in which they could safely practice and refine their newly accumulated stores of social and cultural capital. Even for those students who did not pursue basic science as a career, such skills were invaluable as a dress rehearsal for their future employment.

\section{Conclusions and Suggestions for Future Research}

One's upbringing, class status, and cultural background can have an enormous effect on aspirations and expectations. Our exploration of the efforts of an academic enrichment program to ameliorate the gaps between URM students and majority/white students' cultural and social capital suggests that socialization "after the fact," or communitydirected cultivation, can be valuable. While community-directed cultivation is unlikely to completely replace the "concerted cultivation" of middle-class parents (Lareau 2003), our data suggest that efforts toward expanding habitus and thereby augmenting cultural and social capital may have positive effects for URM college students' academic and career prospects, above and beyond the boost provided by supplementary academic support.

Our findings also suggest that it may be necessary to move beyond our conception of habitus as purely a constraining force, allowing elites to maintain power and prestige (Bourdieu 1990), and to instead consider the ways in which limited habitus may serve as a 
motivator. A majority of BUSPers-nearly $60 \%$ - speak of an intense sense of altruism. This strong desire to help other people "like me" may propel some students to attain mobility even though they lack access to the very forms of capital that facilitate the mobility of more privileged students. Whether programs such as BUSP can marshal such altruistic "agency" to help underrepresented students transform adversity into success is not yet clear, but should be the focus of further study.

\section{Community-Directed Cultivation}

One's habitus sets parameters around that which is imaginable; students cannot aspire to a profession that they have not heard about. Still, early interventions and educational experiences can "prepare the soil" for an infusion of cultural and social capital that is important for individual mobility. The community-directed cultivation strategies that BUSP provides facilitate the acquisition of the specialized set of skills and behaviors peculiar to the academic/scientific community. This community is all but invisible to many students prior to their "socialization" experiences through BUSP and the URE. By keeping students grounded in a (sub)cultural community of URM students and facilitating peer networks, BUSP manages to limit the "discordance" Bourdieu suggested would slow the acceptance of those who "learn" cultural practices outside the home environment (Bourdieu 1984). Over the course of 4 years of support, BUSP students become comfortable with the fact that "people like me" can excel in science careers, and thereby raise their awareness of what is possible. BUSP also provides a specialized "trial field" in which such capital can be cultivated and activated before the "real world" gatekeepers in the fields of academia and the scientific industries are encountered.

Our research suggests that targeted interventions can overcome even strong obstacles for URM students with the desire to achieve permanent mobility through higher education. Our findings also answer the call by Goddard (2003), Astone et al. (1999) and others to move beyond "deficit models" of cultural capital and to instead examine how the various forms of capital might be developed in populations lacking inherited cultural and social capital. The present work's strength is its in-depth qualitative analysis. One limitation, however, is its sample size; we are unable to make definitive comparisons of differential effects by race/ethnicity. Further large-scale, qualitative inquiries into the sometimes competing problems of class, generational status and race/ethnicity are necessary, as well as further exploration of similar programs that aim to increase the population of successful URM college graduates.

Acknowledgments This project was supported by grant 1R01 GM07203 from the MORE program of the NIH. The authors wish to thank Michael Olneck, Merna Villarejo, Amy Barlow, Jennifer Sweeney, Lina Mendez Benavidez, David Orzechowicz, Jane Le Skaife, Dawn Lee Tu, and the anonymous reviewers for feedback and comments on earlier versions of this paper. Thanks also to Eric Sindelar, Michael Lewis and Abhay Prasad for their ongoing support. Order of authorship does not reflect differences in the contributions of the authors; this is a collaborative project.

Open Access This article is distributed under the terms of the Creative Commons Attribution Noncommercial License which permits any noncommercial use, distribution, and reproduction in any medium, provided the original author(s) and source are credited. 


\section{References}

Ajrouch, K. J. (2004). Gender, race, and symbolic boundaries: Contested spaces of identity among ArabAmerican adolescents. Sociological Perspectives, 44(4), 371-391.

Astone, N. M., Nathanson, C. A., Schoen, R., \& Kim, Y. J. (1999). Family demography, social theory, and investment in social capital. Population and Development Review, 25(1), 1-31.

Barlow, A. E. L., \& Villarejo, M. (2004). Making a difference for minorities: Evaluation of an educational enrichment program. Journal of Research in Science Teaching, 41(9), 861-881.

Bauer, K. W., \& Bennett, J. S. (2003). Alumni perceptions used to assess undergraduate research experience. Journal of Higher Education, 74(2), 210-230.

Bell, N. (2008). Graduate enrollment and degrees: 1997 to 2007. Council of Graduate Schools: Office of Research and Policy Analysis.

Bernier, A., Larose, S., \& Soucy, N. (2005). Academic mentoring in college: The interactive role of student's and mentor's interpersonal dispositions. Research in Higher Education, 46(1), 29-51.

Bettie, J. (2003). Women without class: Girls, race, and identity. Berkeley: University of California Press.

Bourdieu, P. (1973). Cultural reproduction and social reproduction. In R. Brown (Ed.), Knowledge, education, and cultural change: Papers in the sociology of education (pp. 71-112). London: Tavistock.

Bourdieu, P. (1984). Distinction: A social critique of the judgment of taste (R. Nice, Trans.). Cambridge: Harvard University Press.

Bourdieu, P. (1986). Cultural capital: The forms of capital. In J. G. Richardson (Ed.), The handbook of theory and research for the sociology of education (pp. 241-258). Stanford: Stanford University Press.

Bourdieu, P. (1990). The logic of practice (Polity Press, Cambridge, Trans.). Stanford: Stanford University Press.

Bowen, G. A. (2006). Grounded theory and sensitizing concepts. International Journal of Qualitative Methods, 5(3), Article 2.

Center for Institutional Data Exchange Analysis. (2000). 1999-2000 SMET retention report. Norman, OK: University of Oklahoma.

Coleman, J. S. (1988). Social capital in the creation of human capital. The American Journal of Sociology (Supplement), 94(S1), S95-S120.

Council of Graduate Schools. (2007). Graduate education: The backbone of American competitiveness and innovation. A Report from the Council of Graduate Schools Advisory Committee on Graduate Education and American Competitiveness. Washington, DC: Council of Graduate Schools.

Dika, S. L., \& Singh, K. (2002). Applications of social capital in educational literature: A critical synthesis. Review of Educational Research, 72(1), 31-60.

Einarson, M. K., \& Matier, M. W. (2005). Exploring race differences in correlates of seniors' satisfaction with undergraduate education. Research in Higher Education, 46, 641-676.

Fordham, S., \& Ogbu, J. (1986). Black students' school success: Coping with the "burden of 'acting white"”. The Urban Review, 18(3), 176-206.

Fox, M. F., Sonnert, G., \& Nikiforava, I. (2009). Successful programs for undergraduate women in science and engineering: Adapting versus adopting the institutional environment. Research in Higher Education, 50(4), 333-353.

Goddard, R. D. (2003). Relational networks, social trust, and norms: A social capital perspective on students' chances of academic success. Educational Evaluation and Policy Analysis, 25(1), 59-74.

Grodsky, E., \& Riegle-Crumb, C. (2010). Those who choose and those who don't. The Annals of the American Academy of Political and Social Science, 627(1), 14-35.

Hassrick, E. M., \& Schneider, B. (2009). Parent surveillance in schools: A question of social class. American Journal of Education, 115(2), 195-225.

Hausmann, L. R. M., Schofield, J. W., \& Woods, R. L. (2007). Sense of belonging as a predictor of intentions to persist among African American and White first-year college students. Research in Higher Education, 48(7), 803-839.

Hebdige, D. (1979). Subculture: The meaning of style. New York: Methuen.

Horvat, E. M., Weininger, E., \& Lareau, A. (2003). From social ties to social capital: Class differences in the relation between school and parent networks. American Educational Research Journal, 40(2), 319-351.

Hurtado, S., Cabrera, N. L., Lin, M. H., Arellano, L., \& Espinosa, L. L. (2009). Diversifying science: Underrepresented student experiences in structured research programs. Research in Higher Education, 50(2), 189-214.

Hurtado, S., Eagan, M. K., Cabrera, N. L., Lin, M. H., Park, J., \& Lopez, M. (2008). Training future scientists: Predicting first-year minority student participation in health science research. Research in Higher Education, 49(2), 126-152. 
Hurtado, S., Han, J. C., Saénz, V. B., Espinosa, L. L., Cabrera, N. L., \& Cerna, O. S. (2007). Predicting transition and adjustment to college: Biomedical and behavioral science aspirants' and minority students' first year of college. Research in Higher Education, 48(7), 841-887.

Jensen, S. Q. (2006). Rethinking subcultural capital. Young: Nordic Journal of Youth Research, 14(3), 257-276.

Jones, M. T., Barlow, A. E. L., \& Villarejo, M. (2010). Importance of undergraduate research for minority persistence and achievement in biology. Journal of Higher Education, 81(1), 82-115.

Kingston, P. W. (2001). The unfulfilled promise of cultural capital theory. Sociology of Education, 74(Extra Issue), 88-99.

Kramer, G. L., Higley, H., \& Olsen, D. (1994). Changes in academic major among undergraduate students. College and University, 69(2), 88-96.

Lareau, A. (2001). Embedding capital in a broader context: The case of family-school relationships. In B. Biddle (Ed.), Social class, poverty, and education (pp. 77-100). London: Routledge Falmer.

Lareau, A. (2003). Unequal childhoods: Class, race, and family life. Berkeley: University of California Press.

Lareau, A., \& Horvat, E. M. (1999). Moments of social inclusion and exclusion: Race, class, and cultural capital in family-school relationships. Sociology of Education, 71(1), 37-53.

Lareau, A., \& Weininger, E. B. (2003). Cultural capital in educational research: A critical assessment. Theory and Society, 32(5/6), 567-606.

Lareau, A., \& Weininger, E. B. (2008). Class and the transition to adulthood. In A. Lareau \& D. Conley (Eds.), Social class: How does it work? (pp. 118-151). New York: Russell Sage Foundation.

Lin, N. (2001). Building a network theory of social capital. In N. Lin, K. Cook, \& R. S. Burt (Eds.), Social capital: Theory and research (pp. 3-29). New York: Aldine De Gruyter.

Lum, L. (2006). Handling "helicopter parents". Diverse: Issues in Higher Education, 23(20), 40-43.

Maldonado, D. E. Z., Rhoads, R., \& Buenavista, T. L. (2005). The student-initiated retention project: Theoretical contributions and the role of self-empowerment. American Educational Research Journal, 42(4), 605-638.

Martin, N. D., \& Spenner, K. I. (2009). Capital conversion and accumulation: A social portrait of legacies at an elite university. Research in Higher Education, 50(7), 623-648.

Merriam, S. B. (1998). Qualitative research and case study applications in education. San Francisco, CA: Jossey-Bass Publishers.

National Academy of Sciences. (2005). Assessment of NIH minority research and training programs: Phase 3. Washington, DC: National Academies Press.

National Science Foundation, Division of Science Resources Statistics. (2009). Women, minorities, and persons with disabilities in science and engineering (NSF 09-305). Washington, DC: National Science Foundation.

National Science Foundation: National Science Board. (2008). Research and development: Essential foundation for U.S. competitiveness in a global economy (NSB 08-03). Arlington, VA: National Science Foundation.

Nisbett, N. (2007). Friendship, consumption, morality: Practising identity, negotiation hierarchy in middleclass Bangalore. Journal of the Royal Anthropological Institute (N.S.), 13, 935-950.

Olneck, M. (2000). Can multicultural education change what counts as cultural capital? American Educational Research Journal, 37(2), 317-348.

Oseguera, L., \& Rhee, B. S. (2009). The influence of institutional retention climates on student persistence to degree completion: A multilevel approach. Research in Higher Education, 50(6), 546-569.

Pascarella, E. T., Pierson, C. T., Wolniak, G. C., \& Terenzini, P. T. (2004). First-generation college students: Additional evidence on college experiences and outcomes. Journal of Higher Education, 75(3), 249-284.

Perna, L., Lundy-Wagner, V., Drezner, N. D., Gasman, M., Yoon, S., Bose, E., et al. (2009). The contribution of HBCUS to the preparation of African American women for stem careers: A case study. Research in Higher Education, 50(1), 1-23.

Shmurak, C. B., \& Handler, B. S. (1992). "Castle of science": Mount Holyoke college and the preparation of women in chemistry, 1837-1941. History of Education Quarterly, 32, 315-342.

Stanton-Salazar, R. D. (1997). A social capital framework for understanding the socialization of racial minority children and youths. Harvard Educational Review, 67(1), 1-40.

Stanton-Salazar, R. D. (2001). Manufacturing hope and despair: The school and kin support networks of U.S.-Mexican youth. New York: Teachers College Press.

Strauss, A., \& Corbin, J. (1990). Basics of qualitative research: Grounded theory procedures and techniques. Newbury Park, CA: Sage. 
Suarez-Balcazar, Y., Orellana-Damacela, L., Portillo, N., Rowan, J. M., \& Andrews-Guillen, C. (2003). Experiences of differential treatment among college students of color. Journal of Higher Education, 74(4), 428-444.

Swartz, D. (1997). Culture and power: The sociology of Pierre Bourdieu. Chicago: The University of Chicago Press.

Thornton, S. (1996). Club cultures: Music, media and subcultural capital. Hanover, NH: Wesleyan University Press.

Tierney, W. G. (1999). Models of minority college-going and retention: Cultural integrity versus cultural suicide. The Journal of Negro Education, 68(1), 80-91.

Tinto, V. (1987). Leaving college: Rethinking the causes and cure of student attrition. Chicago: The University of Chicago Press.

Umbach, P. D., \& Wawrzynski, M. R. (2005). Faculty do matter: The role of college faculty in student learning and engagement. Research in Higher Education, 46(2), 153-184.

University of California, Davis: University Communications. (June, 2009). UC Davis facts: Student headcount by ethnicity (Fall 2008). Compiled on July 29, 2009, from http://facts.ucdavis.edu/.

Villarejo, M., \& Barlow, A. E. L. (2007). Evolution and evaluation of a biology enrichment program for minorities. Journal of Women and Minorities in Science and Engineering, 13(2), 119-144.

Villarejo, M., Barlow, A. E. L., Kogan, D., Veazey, B. D., \& Sweeney, J. K. (2008). Encouraging minority undergraduates to choose science careers: Career paths survey results. CBE Life Sciences Education, 7(4), 394-409.

Yin, R. K. (2003a). Applications of case study research. Applied Social Research Methods Series (Vol. 34, 2nd ed.). Thousand Oaks, CA: Sage Publications.

Yin, R. K. (2003b). Case study research: Design and methods. Applied Social Research Methods Series (Vol. 5, 3rd ed.). Thousand Oaks, CA: Sage Publications. 